\title{
Polymerization of Methyl Methacrylate Initiated by the Benzoin-Pyridine-Carbon Tetrachloride System
}

\author{
Kenzo Inoue, Nagatoshi NaKagawa, and Teiichi Tanigaki* \\ Department of Industrial Chemistry, Niihama Technical \\ College, Niihama, Ehime 792, Japan.
}

(Received October 20, 1975)

\begin{abstract}
A mixture of benzoin, pyridine, and carbon tetrachloride has been found to be an effective initiation system for the polymerization of methyl methacrylate (MMA). The lack of any one component resulted in a remarkably slower rate of polymerization. The $\alpha$-hydroxy ketone group in benzoin has been shown to be necessary to initiate the polymerization of MMA, by comparison with the results of the polymerizations by benzil, hydrobenzoin, or benzoin methyl ether instead of benzoin. The activation energy of the initiation reaction was calculated to be $12.8 \mathrm{kcal} / \mathrm{mol}$ from the overall activation energy of $11.3 \mathrm{kcal} / \mathrm{mol}$, using the values of the propagation and termination energy in the literature. The small activation energy of initiation suggested that the initiation reaction in this system proceeds through a redox mechanism. The initiation mechanism was proposed on the basis of the results of the kinetics and the product analysis.
\end{abstract}

KEY WORDS Radical Polymerization / Methyl Methacrylate / Benzoin / Pyridine / Carbon Tetrachloride / Redox Mechanism / Charge-Transfer Complex /

The formation of charge-transfer complexes of amines with haloalkanes has been shown by many authors; ${ }^{1-11}$ the effects of metal salts ${ }^{2-4}$ and of light $t^{5-10}$ on such a reaction have also been investigated. However, the role of metal salts in the reaction of amines with carbon tetrachloride remains unclear. Both ionic and homolytic mechanisms have been proposed to explain the experimental results. Asscher and Vofsi ${ }^{4}$ have shown that triethanolamine reacts with carbon tetrachloride in the presence of cuprous and ferrous salts to give trichloromethyl radical through a ligand transfer process. Similar results have been obtained by Lautenberger $^{8}$ in the reaction of $n$-buthylamine with carbon tetrachloride in the presence of $\mathrm{Fe}(\mathrm{II})$ or $\mathrm{Cu}(\mathrm{I})$.

The telomerization of vinyl chloride with amines and carbon tetrachloride in the presence of cupric chloride has been shown to initiate its reaction by a trichloromethyl radical formed

* Present address: Department of Industrial Chemistry, Faculty of Engineering, Ehime University, Matsuyama 790. from the decomposition of the complex of amine-metal salts- $\mathrm{CCl}_{4}{ }^{12,13}$ The presence of reducing agents is anticipated to be important for the formation of a trichloromethyl radical in the reaction of amines with carbon tetrachloride. Benzoin has been used as an effective reducing agent in the initiator system for polymerization. For example, Ukita ${ }^{14}$ has shown that the polymerization of vinyl acetate initiated by the $\mathrm{Fe}(\mathrm{III})$ - benzoin-benzoyl peroxide system proceeds via a redox mechanism.

We have found that the benzoin-pyridinecarbon tetrachloride system can serve as an effective radical initiator for vinyl polymerization. This paper describes the mechanism of the polymerization of MMA with this initiator system.

\section{EXPERIMENTAL}

\section{Materials}

Commercial MMA was purified by the usual method and distilled under reduced pressure in a nitrogen stream before use. Benzoin, benzil, and hydrobenzoin were prepared by the usual 
methods. Benzoin methyl ether was prepared from benzoin and methyl iodide in the presence of silver oxide in acetone. The melting points corresponded well with the values reported in the literature. Benzene, pyridine, and carbon tetrachloride were purified by the usual methods. Preparation of the Polymer Containing Benzoin Structure (PSG). ${ }^{15}$

Into a $500-\mathrm{m} l$ three-necked round-bottomed flask, fitted with a stirrer, a reflux condenser, and a dropping funnel, were placed $9.0 \mathrm{~g}$ of polystyrene $\left(M_{w}, 1.87 \times 10^{5}\right), 280 \mathrm{ml}$ of nitrobenzene, and $5.8 \mathrm{~g}$ of aluminum chloride under a nitrogen stream. Phenyl glyoxzal, ${ }^{16}$ which was prepared from the oxidation of acetophenone by $\mathrm{SeO}_{2}$, was admitted from the dropping funnel over a period of $30 \mathrm{~min}$ with stirring. The mixture was stirred for about $15 \mathrm{hr}$ at room temperature. The cold dilute $\mathrm{HCl}(20 \%)$ was added, and the solution was allowed to stand overnight. The organic layer was poured into methanol to precipitate the polymer. The polymer was purified by the reprecipitation method three times from the benzene-methanol system. The yield was $7.0 \mathrm{~g}$ : IR $3400(\mathrm{OH})$ and $1670 \mathrm{~cm}^{-1} \quad(\mathrm{C}=\mathrm{O})$. From the elemental analysis, the benzoin content of this polymer was $6.5 \mathrm{~mol} \%$.

\section{Polymerization Procedure}

Into a glass tube a given amount of carbon tetrachloride, pyridine, and MMA containing benzoin were placed. The glass tubes were degassed under vacuum by the usual freezing and thawing technique and sealed off. Polymerizations were carried out by shaking at $60^{\circ} \mathrm{C}$. The conversion was determined from the weight of the dry polymer. The numberaverage molecular weights were calculated from the following equation in benzene at $25^{\circ} \mathrm{C}:{ }^{17}$

$$
[\eta]=0.57 \times 10^{-4}[\mathrm{M}]^{0.76}
$$

\section{RESULTS AND DISCUSSION}

The initiator system consisting of three components: benzoin (BN), pyridine (Py), and carbon tetrachloride, was found to be effective for the initiation of the polymerization of MMA. As shown in Figure 1, a single component from the system or only two components, such as

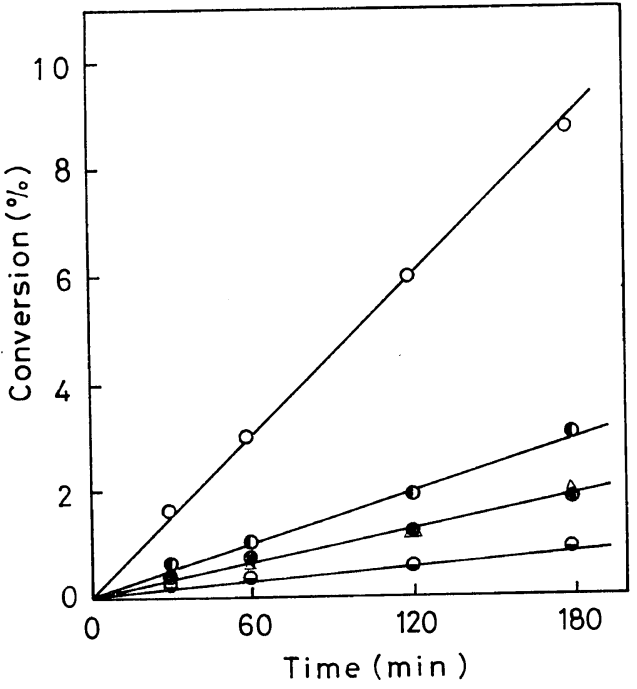

Figure 1. Time-conversion relations for the polymerization of MMA by the initiator system consisting of benzoin, pyridine, and carbon tetrachloride at $60^{\circ} \mathrm{C}:(\bigcirc), \mathrm{BN}-\mathrm{Py}-\mathrm{CCl}_{4} ;(\bigcirc), \mathrm{BN}-\mathrm{Py}$; $(\odot), \mathrm{BN}-\mathrm{CCl}_{4} ;(\ominus), \mathrm{Py}-\mathrm{CCl}_{4} ;(\triangle), \mathrm{BN} ;[\mathrm{M}]_{0}$, $5 \mathrm{ml} ;[\mathrm{BN}], 4 \times 10^{-2} \mathrm{~mol} / l ;[\mathrm{Py}], 1.95 \mathrm{~mol} / l ;\left[\mathrm{CCl}_{4}\right]$, $0.168 \mathrm{~mol} / l$.

$\mathrm{Py}-\mathrm{CCl}_{4}$ or $\mathrm{BN}-\mathrm{CCl}_{4}$, has only a slight capacity to initiate the polymerization of MMA. Only the BN-Py system could initiate the polymerization, but with a slower rate than that by the three components' system. From these results, all three component were found to be necessary to initiate the polymerization effectively. In the polymerization of MMA with three components, the polymerization by two components, the $\mathrm{BN}-\mathrm{Py}$ system, was thought to occur simultaneously. Therefore, the true rate of polymerization of MMA by three components must be corrected by subtracting the conversion in the two components' system from that in the three components' system. Dependence of the rate of polymerization $\left(R_{\mathrm{p}}\right)$ on monomer concentration in benzene solution and on each component's concentration was studied at $60^{\circ} \mathrm{C}$. The initial rate of polymerization exhibited a linear relationship to the square root of each component's concentration, as shown in Figure 2, and was found to be proportional to the monomer concentration. The following equation was derived from these results as the rate equation: 


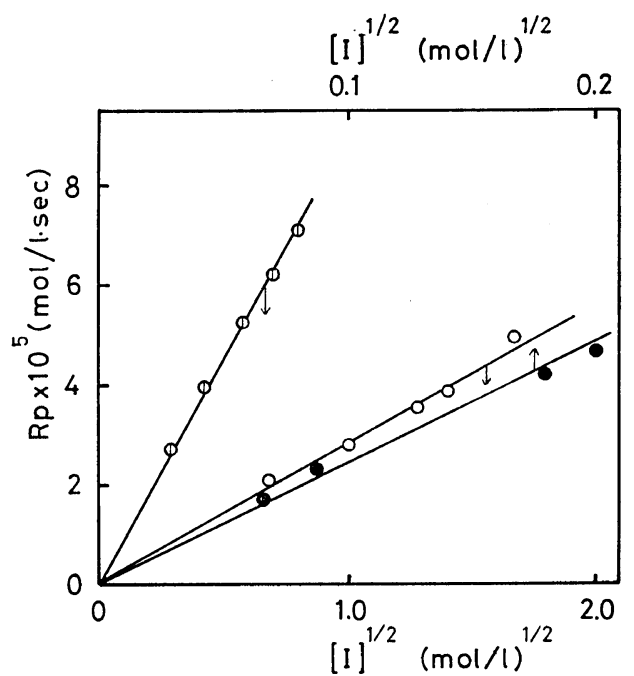

Figure 2. Relationship between $R_{\mathrm{p}}$ and each component concentration: (O), [BN] was changed, [Py], $1.95 \mathrm{~mol} / l,\left[\mathrm{CCl}_{4}\right], 0.168 \mathrm{~mol} / l ;(\bigcirc)$, [Py] was changed, [BN], $4 \times 10^{-2} \mathrm{~mol} / l,\left[\mathrm{CCl}_{4}\right], 0.168 \mathrm{~mol} / l$; (1), $\left[\mathrm{CCl}_{4}\right]$ was changed, [BN], $4 \times 10^{-2} \mathrm{~mol} / l,[\mathrm{Py}]$, $1.95 \mathrm{~mol} / l ;[\mathrm{M}]_{0}, 5 \mathrm{ml}$; temp, $60^{\circ} \mathrm{C}$.

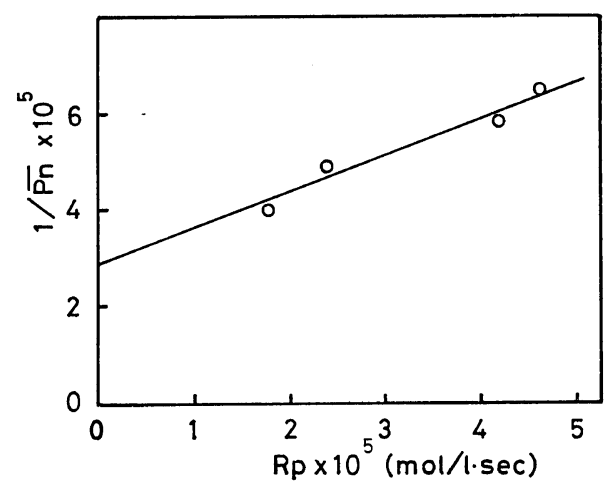

Figure 3. Relationship between $R_{\mathrm{p}}$ and $1 / \bar{P}_{n}$ : [BN], $4 \times 10^{-2}, 3.2 \times 10^{-2}, 7.9 \times 10^{-3}, 4.2 \times 10^{-3} \mathrm{~mol} / l ;$; $[\mathrm{Py}]$, $1.95 \mathrm{~mol} / l ;\left[\mathrm{CCl}_{4}\right], 0.168 \mathrm{~mol} / l$.

$$
R_{\mathrm{p}}=k[\mathrm{BN}]^{1 / 2}[\mathrm{Py}]^{1 / 2}\left[\mathrm{CCl}_{4}\right]^{1 / 2}[\mathrm{MMA}]
$$

The polymerization by the system was inhibited in the presence of oxygen. These results might indicate that the polymerization by the three components' system proceeds through a radical mechanism including bimolecular termination and one mole of each component except the monomer participates in the initiation of the polymerization.
The relationship between $R_{\mathrm{p}}$ and the reciprocal of the number-average degree of polymerization $\left(1 / \bar{P}_{n}\right)$ showed a straight line (Figure 3$)$. The value of $k_{\mathrm{p}} / k_{\mathrm{t}}{ }^{1 / 2}$ was calculated to be 0.15 $(l / \mathrm{mol} \mathrm{sec})^{1 / 2}$ from the slope of the line in Figure 3 and showed a close agreement with that of the radical polymerization of MMA with $\mathrm{AIBN}^{18}$ or $\mathrm{BPO}^{19}$ The apparent overall activation energy of polymerization with the initiator system of $\mathrm{BN}-\mathrm{Py}-\mathrm{CCl}_{4}$ was calculated to be $11.3 \mathrm{kcal} / \mathrm{mol}$. Therefore, the activation energy for the initiation reaction was obtained as 12.8 $\mathrm{kcal} / \mathrm{mol}$ by using the reported activation energy for the propagation and termination. ${ }^{20}$ This value was quite small as compared with that of ordinary radical initiators. ${ }^{21}$ From these results it was obvious that this system produced initiating radicals by a redox interaction.

In order to study the action of benzoin on the initiation reaction, benzil, hydrobenzoin, or benzoin methyl ether, which have no or a smaller reducing action, was used as one component in the initiator system in the place of benzoin. As shown in Figure 4, the rates of

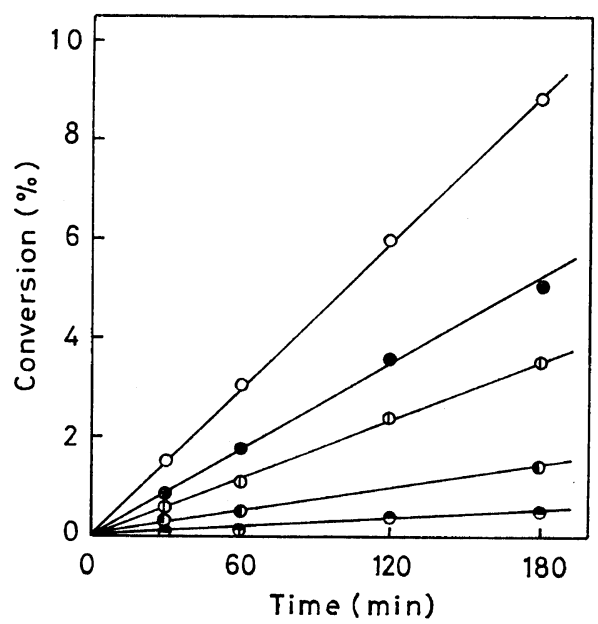

Figure 4. The comparison of the rate of polymerization with initiator systems of benzoin, benzil, hydrobenzoin, or benzoin methyl ether in the presence of a constant concentration of pyridine and carbon tetrachloride at $60^{\circ} \mathrm{C}$ : (O), [BN], $4 \times 10^{-2} \mathrm{~mol} / l$; (1), [Benzoin methyl ether], $4 \times 10^{-2} \mathrm{~mol} / l$; (O), [Benzil], $4 \times 10^{-2} \mathrm{~mol} / l$; (O), [BN], $7.9 \times 10^{-3} \mathrm{~mol} / l$; (D), [Hydrobenzoin], $7.9 \times$ $10^{-3} \mathrm{~mol} / l ; \quad[\mathrm{Py}], 1.95 \mathrm{~mol} / l ; \quad\left[\mathrm{CCl}_{4}\right], 0.168 \mathrm{~mol} / l$; $[\mathrm{M}]_{0}, 5 \mathrm{ml}$. 
polymerization of MMA with those initiator systems decreased in comparison with that by the $\mathrm{BN}-\mathrm{Py}-\mathrm{CCl}_{4}$ system. Therefore benzoin, which has an $\alpha$-hydroxy ketone group, seems to act as a reducing agent for the formation of an initiating radical in the initiation reaction.

Benzoin is known to form the benzoin anion radical $[\mathrm{I}]$ during the course of its oxidation in alkaline alcoholic solution: ${ }^{22}$

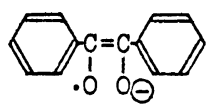

It has been presumed that this anion radical is formed by the interaction between benzoin and pyridine and then participates in the initiation reaction. However, the radical anion could not be detected in the reaction of benzoin with pyridine by ESR spectroscopy. Furthermore, the benzoin anion radical produced from the reaction of benzoin with $\mathrm{NaOH}$ could not initiate the polymerization at $60^{\circ} \mathrm{C}$. Therefore, the anion radical does not participate in the initiation reaction.

In the polymerization of MMA with the BN$\mathrm{Py}-\mathrm{CCl}_{4}$ system, carbon tetrachloride was replaced with chloroform or methylene chloride. The initiation activities of these halides increased in the following order: $\mathrm{CH}_{2} \mathrm{Cl}_{2}<\mathrm{CHCl}_{3}<\mathrm{CCl}_{4}$. The conversions for $3 \mathrm{hr}$ at $60^{\circ} \mathrm{C}$ were $2.4 \%<$ $2.6 \%<9.0 \%$, respectively. This order coincides with the decreasing bond-dissociation energy of the carbon-halogen bonds in haloalkanes and the stability of the charge-transfer complexes between amine and halide. ${ }^{6}$

To clarify the initiating radical, the graft polymerization of MMA on the polymer containing the benzoin structure (PSG) was carried out. The rate of polymerization with the initiator system of PSG-Py- $\mathrm{CCl}_{4}$ increased remarkably as compared with that of the PSG-Py system, in a similar manner to the results in the benzoin system. Unfortunately, when PSG was used as one component of the initiator system, the graft polymer formed in the polymerization was difficult to separate from the polymer mixture. Therefore, the gelled PSG (GPSG: benzoin content, $1.4 \mathrm{~mol} \%$ ), which was insoluble in organic solvents, was used. The relationships between given amounts of GPSG

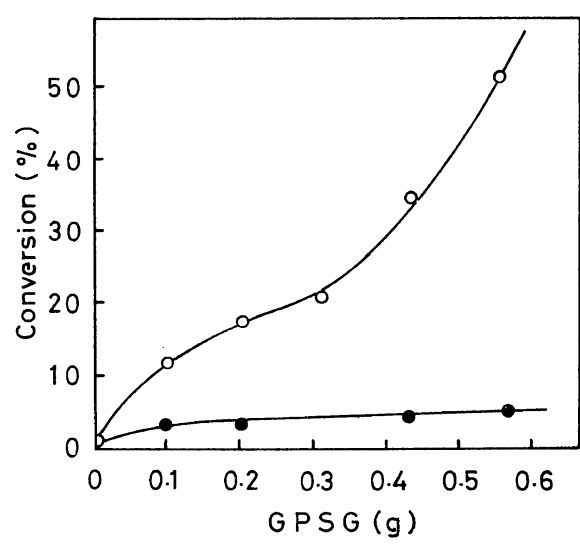

Figure 5. Relationship between conversion and added GPSG concentration at $60^{\circ} \mathrm{C}$ : (O), GPSG$\mathrm{Py} ;(\bigcirc), \mathrm{GPSG}-\mathrm{Py}-\mathrm{CCl}_{4} ;[\mathrm{Py}], 1.95 \mathrm{~mol} / l ;\left[\mathrm{CCl}_{4}\right]$, $0.168 \mathrm{~mol} / l ;[\mathrm{M}]_{0}, 5 \mathrm{ml}$; time, $4 \mathrm{hr}$.

Table I. Polymerization of MMA initiated by the GPSG-Py- $\mathrm{CCl}_{4}$ system ${ }^{\mathrm{a}}$

\begin{tabular}{cccccr}
\hline No. ${ }^{b}$ & $\begin{array}{c}\text { Added } \\
\text { GPSG, } \\
\mathrm{g}\end{array}$ & $\begin{array}{c}\text { Yield, } \\
\mathrm{g}\end{array}$ & $\begin{array}{c}\text { Conver- } \\
\text { sion, } \\
\%\end{array}$ & $\begin{array}{c}\text { Graft } \\
\text { polymer, } \\
\mathrm{g}\end{array}$ & $\begin{array}{c}\text { Graft } \\
\text { effi- } \\
\text { ciency, } \\
\%\end{array}$ \\
\hline 1 & 0.4179 & 0.1797 & 3.82 & 0.0453 & 25.21 \\
2 & 0.5354 & 0.2158 & 4.59 & 0.0520 & 24.10 \\
3 & 0.4153 & 1.7181 & 36.56 & 0.1035 & 6.02 \\
4 & 0.5358 & 2.3941 & 50.94 & 0.0434 & 1.81
\end{tabular}

a $[\mathrm{Py}], 1.95 \mathrm{~mol} / l ;\left[\mathrm{CCl}_{4}\right], 0.168 \mathrm{~mol} / l ; \mathrm{MMA}, 5 \mathrm{ml}$; time, $4 \mathrm{hr}$; temp, $60^{\circ} \mathrm{C}$.

b Initiator system: No. 1 and 2, GPSG-Py; No. 3 and 4, GPSG-Py- $-\mathrm{CCl}_{4}$.

and conversion are shown in Figure 5. In the case of the GPSG-Py initiator system, the GPSG has only a slight effect on the rate of polymerization of MMA, even at high concentrations of GPSG. However, the rate of polymerization increased with increasing GPSG on addition of carbon tetrachloride. As shown in Table I, the graft efficiency showed a small value for the latter system. These results may be explained by the assumption that in the case of the GPSG-Py- $\mathrm{CCl}_{4}$ system, a trichloromethyl radical was produced as an initiating radical, while on the other hand in the case of the GPSG-Py system, a GPSG radical was formed and initiated the polymerization from the site of GPSG to give a graft copolymer 
with a slower rate than that by the trichloromethyl radical.

In order to confirm this assumption, the reaction of benzoin, pyridine, and carbon tetrachloride in the absence of monomer was carried out at $60^{\circ} \mathrm{C}$. From gas chromatographic and IR spectra analysis of the reaction products, chloroform and benzil were detected. Moreover, the water extract from the reaction mixture gave a precipitate of silver chloride when a solution of silver nitrate was added, indicating the generation of chloride anion in this reaction.

Recently, Smith et al. ${ }^{23}$ proposed that the copper acetate-catalyzed reaction between amine and carbon tetrachloride proceeds by a combination of radical and ionic steps, and that the following mechanism could be assumed in the case of tertiary amine:

$$
\begin{aligned}
& \left.\left(\mathrm{RCH}_{2}\right)_{3} \mathrm{~N}+\mathrm{CCl}_{4} \rightleftharpoons\left[\left(\mathrm{RCH}_{2}\right)_{3} \mathrm{~N}--\mathrm{CCl}_{4}\right] \text { ( } 1\right) \\
& {\left[\left(\mathrm{RCH}_{2}\right)_{3} \mathrm{~N}---\mathrm{CCl}_{4}\right] \stackrel{\mathrm{Cu}^{2+}}{\longrightarrow}\left(\mathrm{RCH}_{2}\right)_{3} \stackrel{+}{\mathrm{N}}+\mathrm{Cl}^{-}+\cdot \mathrm{CCl}_{3}}
\end{aligned}
$$

$$
\begin{aligned}
& \left(\mathrm{RCH}_{2}\right)_{3} \stackrel{+}{\mathrm{N}}+\left(\mathrm{RCH}_{2}\right)_{3} \mathrm{~N} \\
& \longrightarrow\left(\mathrm{RCH}_{2}\right)_{3} \stackrel{+}{\mathrm{N}} \mathrm{H}+\left(\mathrm{RCH}_{2}\right)_{2} \mathrm{~N} \cdots \mathrm{CHR} \\
& \stackrel{\left(\mathrm{RCH}_{2}\right)_{3} \mathrm{~N}+\cdot \mathrm{CCl}_{3}}{\longrightarrow}\left(\mathrm{RCH}_{2}\right)_{2} \mathrm{~N} \cdots \mathrm{CHR}+\mathrm{CHCl}_{3}
\end{aligned}
$$

$$
\begin{gathered}
\left(\mathrm{RCH}_{2}\right)_{2} \mathrm{~N} \cdots \mathrm{CHR}+\mathrm{CCl}_{4} \\
\longrightarrow\left(\mathrm{RCH}_{2}\right)_{2} \mathrm{NCHR}+\cdot \mathrm{CCl}_{3} \\
\stackrel{\mathrm{Cl}}{\longrightarrow}
\end{gathered}
$$

$$
\begin{aligned}
& \left(\mathrm{RCH}_{2}\right)_{2} \mathrm{~N} \cdots \mathrm{CHR}+\cdot \mathrm{CCl}_{3} \\
& \longrightarrow\left(\mathrm{RCH}_{2}\right)_{2} \stackrel{+}{\mathrm{N}}=\mathrm{CHR}+\mathrm{CCl}_{3}^{-}
\end{aligned}
$$

In this reaction scheme, copper ions catalyze only the initiation reaction process, making the overall reaction rate larger. In addition, it is known that the mixtures of $n$-buthylamine and carbon tetrachloride possess oxidizing power. ${ }^{24}$ The interaction between pyridine and carbon tetrachloride has been suggested by Shape and Walker. ${ }^{25}$ Therefore it is thought that this complex has the same action with respect to benzoin. In the polymerization of MMA by the $\mathrm{BN}-\mathrm{Py}-\mathrm{CCl}_{4}$ system, benzoin is thought to act as a reducing agent for the formation of trichloromethyl radical. Accordingly, the following mechanism is proposed: a complex is formed between pyridine and carbon tetrachloride, and then the initiating trichloromethyl radical is produced by the interaction between benzoin and the complex, as shown in the following equation:

$$
\begin{aligned}
& { }_{\mathrm{N}}^{\mathrm{N}}+\mathrm{CCl}_{4} \rightleftharpoons\left[\mathrm{N} \cdot \mathrm{CCl}_{4}\right] \\
& {\left[\mathrm{N}_{\mathrm{N}}^{\mathrm{BN}} \cdot \mathrm{CCl}_{4}\right] \stackrel{\mathrm{BN}}{\longrightarrow} \cdot \mathrm{CCl}_{3}+\mathrm{N}_{\mathrm{HCl}}+}
\end{aligned}
$$

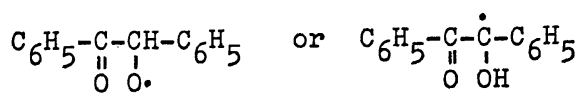

The benzoin radical formed in eq 8 is expected to react with a trichloromethyl radical to give chloroform and benzil, in agreement with the experimental results of the reaction without monomer. The mechanism of the reaction of the complex, $\mathrm{Py}-\mathrm{CCl}_{4}$, with benzoin remains unclear. More detailed discussion will be done later using the future experimental results of the reaction of the complex with substituted benzoin.

\section{REFERENCES}

1. R. F. Collins, Chem. Ind. (London), 704 (1957).

2. G. J. Beich1, J. E. Colwell, and J. G. Miller, ibid., 203 (1960).

3. H. Williams, ibid., 900 (1960).

4. (a) M. Asscher and D. Vofsi, J. Chem. Soc., 2261 (1961); (b) M. Asscher, Chem. Ind. (London), 1430 (1965).

5. D. P. Stevenson and G. M. Coppinger, J. Amer. Chem. Soc., 84, 149 (1962). 
6. K. M. C. Davis and M. F. Farmer, J. Chem. Soc., Sect. B, 28 (1967).

7. G. Drefahl and G. Heublein, J. Prakt. Chem., [4], 31, 76 (1966).

8. W. J. Lautenberger, E. N. Jones, and J. G. Miller, J. Amer. Chem. Soc., 90, 1110 (1968).

9. K. G. Hancock and D. A. Dickinson, J. Org. Chem., 39, 331 (1974).

10. C. J. Biaseller and J. G. Miller, J. Amer. Chem. Soc., 96, 3813 (1974).

11. J. R. L. Smith and Z. A. Malik, J. Chem. Soc., Sect. B, 617 (1970).

12. T. Asahara, M. Seno, and C. C. Wu, Bull. Chem. Soc. Japan, 43, 1127 (1970).

13. B. Bontevin and Y. Pietranta, Tetrahedron Letters, 887 (1973).

14. J. Ukita, Kobunshi Kagaku (Chem. High. Polymers), 10, 358 (1953).

15. Y. Kurusu, H. Nishinaga, and M. Okawara, Makromol. Chem., 138, 49 (1970).

16. "Organic Syntheses," Coll. Vol. II, E. C.
Horning, Editor-in-Chief, John Wiley \& Sons, Inc., New York, N.Y., 1943, p 509.

17. P. J. Flory, "Principles of Polymer Chemistry", Cornell University Press, Ithaca, N.Y., 1953, p 312.

18. M. Imoto, T. Otsu, and Y. Harada, Makromol. Chem., 65, 180 (1963).

19. J. Bevington, Trans. Faraday Soc., 53, 997 (1957).

20. M. Mackay and H. W. Melville, ibid., 45, 323 (1949).

21. J. P. Van Hook and A. V. Tobolsky, J. Amer. Chem. Soc., 80, 779 (1958).

22. J. L. Ihring and R. G. Galdwell, ibid., 78, 2097 (1956).

23. J. R. L. Smith and Z. A. Malik, J. Chem. Soc., Sect. B, 920 (1970).

24. E. N. Jones, W. J. Lautenberger, P. A. Willerment, and J. G. Miller, J. Amer. Chem. Soc., 92, 2946 (1970).

25. A. N. Shape and S. Walker, J. Chem. Soc., Sect. B, 157 (1962). 